\title{
Research and Application of Stress and Strain Testing Method for Plain Concrete Pile
}

\author{
Qinghua Zhu ${ }^{1}$, Weilong Zuo ${ }^{1 *}$, Peng $\mathrm{Xu}^{1}$, Hongyu $\mathrm{Wang}^{2}$ \\ ${ }^{1}$ Jiangsu Surveying and Design Institute of Water resources Co., Ltd., Yangzhou 225127, China; \\ 2 Jiangsu Water Conservancy Construction Bureau, Nanjing 210029, China;
}

\begin{abstract}
At present, the stress-strain test of pile body mainly focuses on precast pile and cast-in-place pile with reinforcement, and this is mainly because the pre-assembly of test components can be carried out in the pile body or reinforcement cage before the prefabricated pile is formed. When the pile is formed, it could be embedded together with the pile body or reinforcement cage. But for the cast-in-place plain concrete pile field test research report is rare. In view of the shortcomings of the existing test methods in the test of plain concrete piles, the resistance strain gauge and inclinometer are improved to realize their application in the field test of plain concrete piles, which is employed for the deformation characteristics test of plain concrete pile under horizontal load. The test results show the applicability of the improved test method, which provides useful references for similar research.
\end{abstract}

\section{Introduction}

In the study of load transfer law and bearing behavior of pile, the test of stress and strain is an essential basic link. Usually, the strain distribution along the length of the pile is measured by embedding test elements in the pile. Traditional test elements include steel bar stress gauge, earth pressure box, sliding micrometer, resistance strain gauge, rod strain gauge and sliding inclinometer ${ }^{[1-5]}$. In recent years, with the development of science and electronic technology, the testing method using fiber Bragg grating and other components appeared ${ }^{[6-7]}$. The measurement accuracy of these test components is not only determined by their own properties and pile properties, but also affected by the setting and embedding methods.

At present, the stress-strain test of pile body is mainly aimed at prefabricated pile and cast-in-place pile with reinforcement. This is mainly because the prefabricated pile can be pre-installed with test components before pile forming, and the components are embedded together with the pile body during pile forming; for cast-in-place pile with reinforcement, the components can be bound or welded to the reinforcement cage when the reinforcement cage is hoisted, which is easier to realize the preinstalled Buried. For the cast-in-place plain concrete pile, the model test is mainly carried out in the model groove, while the field measurement research is rarely reported, mainly because the installation of stress gauge and strain gauge is relatively difficult. In view of the great difference between the indoor test and the actual situation, the test results are difficult to guide the engineering

\footnotetext{
*Corresponding author's e-mail: vlong066@163.com
}

practice, only full-scale field test is carried out, Only by measuring the stress and strain of the pile can we really grasp the load transfer law of the pile body and guide the engineering practice.

In this paper, based on the analysis of the existing test methods, the resistance strain gauge and inclinometer method are improved to realize their application in the field test of plain concrete pile. The deformation characteristics of plain concrete pile under horizontal load are tested completely. The test results show the applicability of the improved test method.

\section{Overview of existing testing methods}

The following is a brief introduction of several commonly used test components and their conventional embedding scheme, and through analysis and summary of the existing scheme in the application of plain concrete pile problems.

\subsection{Steel bar stress meter method}

Many scholars measure the stress of pile body by installing steel bar stress meter on the pile body. For the cast-in-place pile with reinforcement, the steel stress meter shall weld a main reinforcement on the reinforcement cage, or a full-length steel bar welded with the reinforcement stress meter shall be bound to the reinforcement cage, and then it shall be hoisted into the pile hole to complete the embedding. For the plain concrete or cement soil mixing pile, some scholars have embedded the steel bar welded with the steel bar stress 
meter into the drilling hole or put the steel bar into the hole after the pile is completed. The signal line of the steel bar stress meter in this method needs to be embedded from the burying position to the outside of the pile hole. In the pile body, it is easy to be affected by the pile forming, and the survival rate is not high. At the same time, the ideal matching between the steel bar stress meter and the concrete could not be achieved. The existence of steel bar also changes the quality of plain concrete pile. When measuring, the stress will concentrate on the steel bar, resulting in the deviation between the result and the actual situation It is not feasible to use the method in the test of plain concrete, especially in the horizontal load test.

\subsection{Resistance strain gauge method}

The resistance strain gauge transforms the strain of the measured point into the resistance change of the strain gauge through the joint deformation of the strain gauge and the pile. This method needs to stick strain gauge on the concrete pile, and the strain gauge needs to be pasted on a smooth plane, so it is often used in precast pile and indoor model test. There is no smooth plane in cast-in-place pile, so the method of directly pasting strain gauge cannot be applied.

\subsection{Pile deformation measured by inclinometer}

The inclinometer pipe is embedded by drilling holes at the predetermined position of the pile body or binding on the reinforcement cage to make the pipe contact with the soil closely and truly reflect the lateral displacement of the pile body. During the test, the inclinometer is used to complete the measurement through the groove guide rail on the inclinometer pipe. The lateral displacement at different depths can be calculated by measuring the pile shaft curve under different loads. According to the stiffness of the pile body, the lateral displacement at different depths can be calculated The strain of pile body or converted stress. It is difficult to ensure that the inclinometer pipe is in the middle of the pile, so its application is limited.

\subsection{Fiber grating method}

The measurement system is composed of fiber Bragg grating sensor. The system uses the sensitive effect of fiber grating sensor on stress and strain, and converts the stress and strain of pile body caused by load into the measurement of light wave wavelength. This method is developed in recent years and has the characteristics of good reliability, strong anti-interference ability and high measurement accuracy. The disadvantage of this method lies in the cost, which is about 30000 yuan / 10m high, and its cost is directly related to the required accuracy. Optical fiber is made of $\mathrm{SiO} 2$ material, which is easy to be broken during construction, resulting in data loss.

\section{Selection and implementation of test methods}

When the author participated in the research, it is necessary to measure the strain or deformation of $\mathrm{MC}$ composite pile under horizontal load. In view of the existing test methods, resistance strain gauge method and inclinometer test method, the main problems are embedding and guarantee measures. The author has researched and developed the corresponding scheme.

\subsection{Scheme of resistance strain gauge method}

The size of $40 \mathrm{~mm} \times 20 \mathrm{~mm}$ PVC wire slot is used as the carrier of strain gauge. The wire slot provides a necessary flat working surface for the strain gauge, and the wire slot can also protect the conductor from the damage of coarse-grained materials when pouring concrete. The cable trough has low deformation modulus and good ductility, which does not affect the stress and deformation performance of the pile. Open the wire slot, paste the strain gauge at the designated position, extend the conductor, and pass the conductor out of the slot for the trunking of the pasted strain gauge. The design drawing of the scheme is shown in Figure 1.

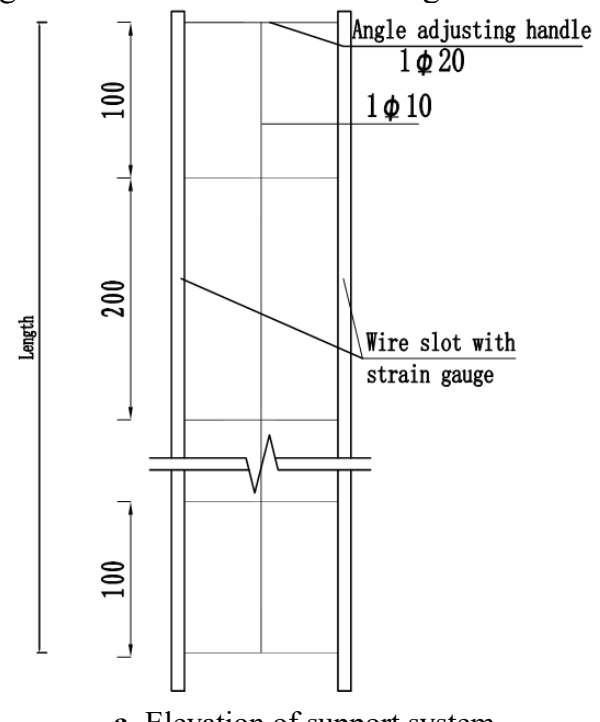

a. Elevation of support system

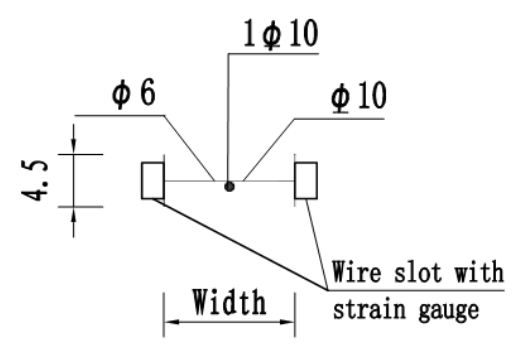

b. Top view of support system

Fig 1 Design of support system

During implementation, the trunking with strain gauges and conductors is fixed to the support system, as shown in Figure 2-3. The support system consists of a bracket and a positioning frame. Although the positioning support is reinforced with large rigidity and high strength, its size is slightly smaller than the pile hole, 
so it can be used as the support of the positioning support to ensure that the position of the support is in the center of the pile. In theory, the strain of the pile center is 0 under the action of horizontal force, which does not affect the stress and deformation performance of plain concrete pile. Lift the support with the pile frame and put it into the pile hole. Rotate the angle rotation handle and adjust the support angle so that the trunking of the left and right groups of strain gauges is symmetrical about the center, and the connecting line coincides with the direction to be measured. After the hoisting and positioning are completed, the concrete is poured and buried.

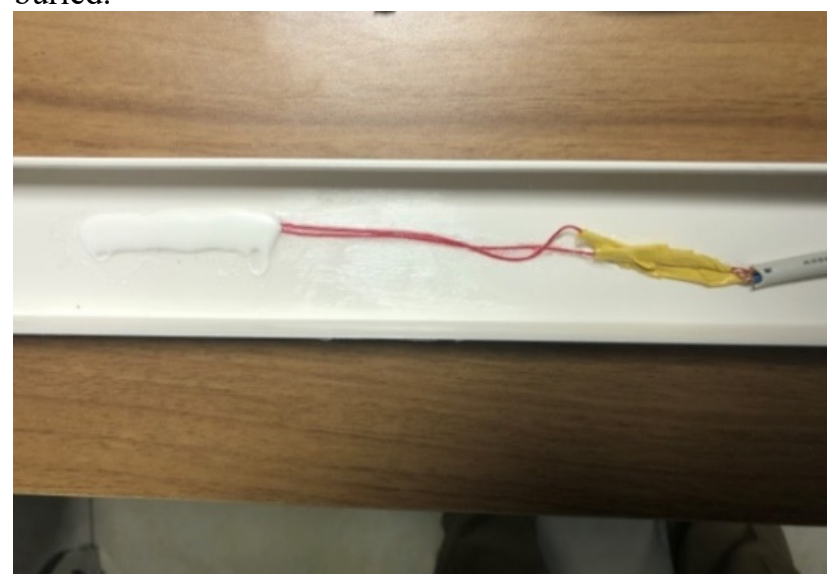

Fig2 PVC-40 wire slot with train gauge

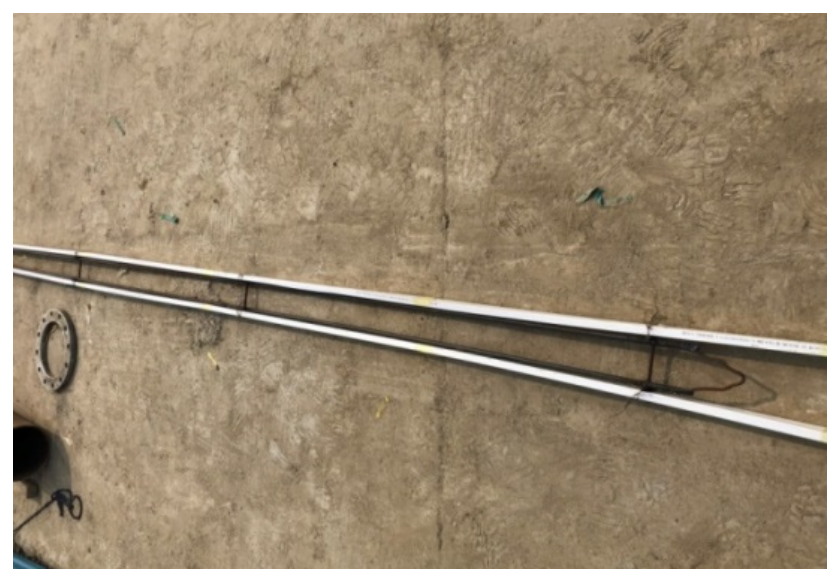

Fig 3 Support system with strain gauge and PVC wire slot

\subsection{Inclinometer test scheme}

The inclinometer pipe embedded in the pile body is an important means to measure the deflection curve of the pile body under horizontal load. In order to ensure the accuracy and correctness of the measurement and reduce the influence of the inclinometer pipe on the deformation characteristics of the pile body, the inclinometer pipe should be embedded in the middle to ensure that the cross section of the inclinometer pipe and the cross section of the pile are concentric circles. For the pile with reinforcement cage, the inclinometer pipe can be embedded by using the reinforcement cage and the frame bar on the reinforcement cage. Aiming at the problem that the inclinometer pipe in the plain concrete pile is easy to deviate from the center, the positioning plate frame is designed to ensure that the inclinometer pipe is concentric with the pile to be measured. The positioning plate frame is welded with $8 \mathrm{~mm}$ smooth steel bar. If the reinforcement is too thick or ribbed non smooth steel bar is easy to affect the blanking of coarse-grained material and block the pile hole; if the reinforcement is too thin, the supporting force is insufficient. The disk rack is composed of inner plate, outer plate and support, the inner plate is used to fix the inclinometer pipe; the outer plate supports the hole wall of pile hole to ensure the center of the whole system is in the middle; the inner and outer plates work together through the support brace, and the diagram is shown in Fig. 4.

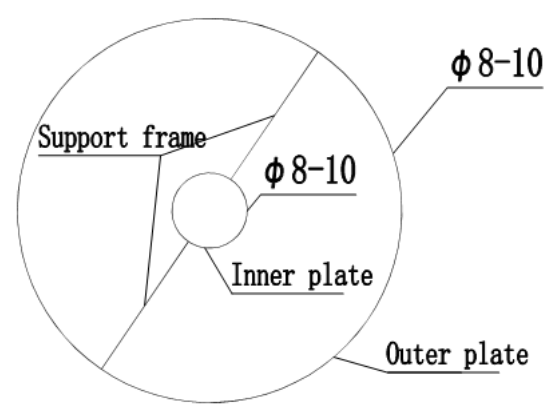

Fig.4 Schematic diagram of positioning tray

When using, the hole diameter of plain concrete pile and the outer diameter of inclinometer pipe to be embedded shall be confirmed. The inner diameter of inner hole of tray frame is the outer diameter of inclinometer hole $+1 \mathrm{~cm}$, and the outer diameter of outer disk is the diameter of hole forming or inner diameter of steel pipe sinking tube $-2 \mathrm{~cm}$. During pile forming, the panel frame shall be connected with the inclinometer pipe, set the positioning plate frame, and fix the screws. The spacing of the fixed plate frame shall be $2-4 \mathrm{~m}$. It shall be determined according to the diameter of the pile hole, and the small spacing shall be used for the large hole diameter. If the spacing is too small, it may hinder the coarse-grained materials and cause blockage; if the spacing is too small, it could not provide enough support, and the inclinometer tube between the rack and the tray may deviate from the center. It is extended to the specified length section by section, and inserted into the pile hole at the same time.)

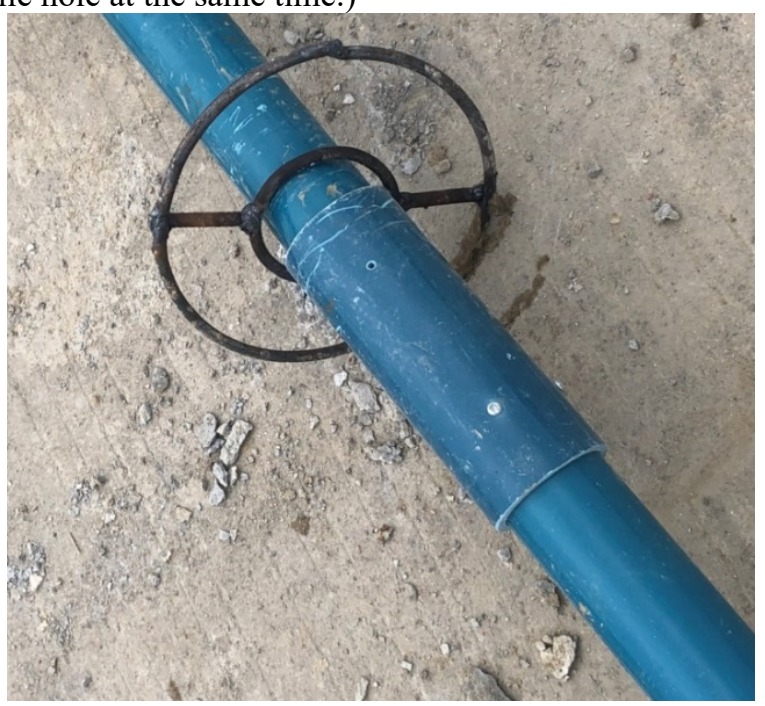

Fig.5 Inclinometer tube support 


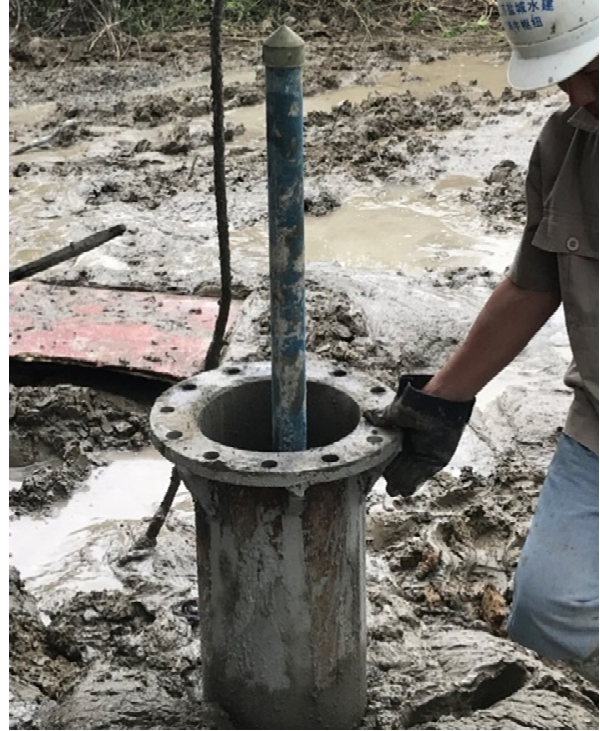

Fig.6 Embedded Pile inclinometer pipe

Rotate the angle of the inclinometer pipe to make the groove track of the inclinometer pipe in the direction to be measured. After the angle is adjusted, the concrete is poured to complete the embedding.

\section{Application of improvement scheme}

The appeal scheme is applied in the horizontal static load test of $\mathrm{MC}$ reinforced composite pile. In the field test, a group of two test piles are used as reaction piles to load the top. Strain gauges are embedded in one group of test piles to measure the strain of pile body through strain gauge, and the other pile is embedded with inclinometer to measure the bending curve of pile body.

The strain results of the pile body under load are measured by the embedded strain gauge. Fig. 7 shows the strain distribution curve of the rigid composite pile under horizontal load. The deflection of the pile body is measured by the inclinometer tube embedded in the pile body. The typical displacement curve of the pile body under various loads is shown in Fig.8.

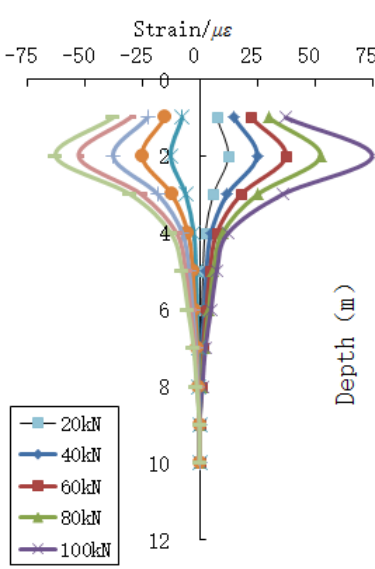

Fig. 7 Test results of strain gauge

These test results show that the design effect of the test method is realized, which lays a good foundation for the later research on the mechanical characteristics of pile body.

\section{Conclusion}

This paper first introduces the commonly used pile stress-strain testing methods. These methods have certain applicable conditions and limitations. In the specific implementation, it is necessary to use them flexibly according to the site conditions. If necessary, certain measures should be taken to ensure the accuracy and smooth completion of the test results. In view of the shortcomings of the existing test methods in the test of plain concrete pile, the resistance strain gauge and inclinometer are improved to realize their application in the field test of plain concrete pile. The deformation characteristics of plain concrete pile under horizontal load are tested completely. The test results show the applicability of the improved test method.

\section{Acknowlegments}

This worked was supported by Jiangsu water conservancy science and technology project (No. 2017017).

\section{Reference}

1. Fei Liya, Huang Xuefeng. Experimental Research on Deformation Pattern of Unsaturated Loess Rocksocketed Bored Piles Under Horizontal Loads [J].Construction Technology,2011, 40(10):74-77.

2. Wu Youping, Liu Jie, He Jie. On the Stress Testing of Cement-Soil Piles [J]. Journal of Hunan University of Technology,2012,26(1):23-26.

3. CHEN Shang-qiao. On the Stress Testing of Cement-Soil Piles [J].Chinese Journal of Rock Mechanics and Engineering,2005,24(7):1267-1271.

4. ZHANG Bi-sheng,LIU Yang,WU Jian,etc. A Comparison of Strain Test Methods of Pile Foundation Models [J]. Journal of Nanjing Institute of Technology( Natural Science Edition) ,2013,11 (4) :23-27.

5. SHEN Yongjiang, SUN Hongyue, SHANG Yuequan, etc.. On the Stress Testing of Cement-Soil Piles [J].Chinese Journal of Rock Mechanics and Engineering,2009,28(S2):3591-3596.

6. Zhang Lei, Zhang Xinkui, Liu Shun,etc. Application of grating sensor in internal force test of precast pile[J]. Survey science and technology,2014(S1): 90-93.

7. Gao Luchao, Dai Guoliang, Gong Weiming, etc. Application of FBG sensors in self- balanced test method for bearing capacity of large- diameter castin- place piles[J].Journal of southeast university ( Natural Science Edition) ,2019,49(4):688-695 . 